\title{
A DESIGUALDADE DE GÊNERO NA FÓRMULA 1, FUTEBOL E RUGBY: Desconstrução Discursiva
}

http://dx.doi.org/10.21527/2176-6622.2021.56.10098

Recebido em: 15/1/2020

Modificações solicitadas em: 20/4/2020

Aceito em: 4/1/2021

Carla Bertoncini Universidade Estadual do Norte do Paraná - Uenp. Jacarezinho/PR, Brasil; Unifio - Ourinhos/SP, Brasil.

Tayana Roberta Muniz Caldonazzo

Autora correspondente. Universidade Estadual do Norte do Paraná - Uenp. Av. Getúlio Vargas, 850. Jacarezinho/PR, Brasil. CEP 86400-000. http://lattes.cnpq.br/9759779920993502. https://orcid.org/0000-0001-8507-0689. tayana.rmc@gmail.com

\section{RESUMO}

O presente trabalho trata da desigualdade de gênero nos esportes, possuindo um viés interdisciplinar entre Direito Constitucional e seu diálogo com questões de gênero. Objetiva-se demonstrar que há um discurso - criado em um contexto de manutenção de poder masculino - que contribui para as desigualdades existentes no campo esportivo. Utilizou-se o método dedutivo, além de pesquisas bibliográficas e eletrônicas em teses, livros, dissertações, periódicos e notícias. Sobre estas, recorreu-se à Análise de Discurso (AD) baseada em Foucault (2008). Como resultados, identificou-se a ilegitimidade de se recorrer à Biologia para justificar a exclusão feminina em modalidades e barreiras à integração igualitária entre mulheres e homens, concluindo-se que os discursos, no campo esportivo, podem ser influenciados por relações de poder que perpetuam a hegemonia masculina, razão pela qual devem ser desconstruídos e contextualizados.

Palavras-chave: Igualdade substancial; relação de poder; futebol; fórmula 1, Rugby.

\section{GENDER INEQUALITY IN FORMULA 1, FOOTBALL AND RUGBY: DISCURSIVE DECONSTRUCTION}

\section{ABSTRACT}

This is a study about gender inequality in sports, with an interdisciplinary bias between Constitutional Law and its dialogue with Gender issues. The objective is to demonstrate that there is a discourse - created in a context of maintaining male power - that contributes to the existing inequalities in the sports field. The deductive method was used, in addition to bibliographic and electronic research in theses, books, dissertations, periodicals and news. About news, the Discourse Analysis (AD) based on Foucault (2008) was used. As results, have been identified the illegitimacy of using biology to justify the feminine exclusion in modalities and barriers to the equalitarian integration between women and men, concluding that the speeches, in the sports field, can be influenced by power relations that perpetuate the masculine hegemony, reason why they must be deconstructed and contextualized.

Keywords: Substantial equality. Femininity. Football. Formula 1. Rugby. 


\section{INTRODUÇÃO}

A presente pesquisa parte de uma análise interdisciplinar, envolvendo o diálogo entre Direito Constitucional e gênero, com o objetivo de demonstrar os discursos que contribuem para as desigualdades injustificadas entre os sexos no mundo do esporte e a importância de desconstruí-los. Justificou-se o trabalho na medida em que referidas crenças tendem a manter barreiras à integração feminina no esporte.

De fato, considerando o trabalho de Monteiro e Formentin (2019) e reportagem de Nina (2019), nota-se que ainda há dúvidas sobre a capacidade física de mulheres para competir na Fórmula 1. Além disso, Camargo e Kessler (2017) defendem que o futebol feminino ainda não possui o mesmo prestígio da modalidade masculina. Beleza e feminilidade são objetos de preocupação, conforme expõe Goellner (2005). Bettine, Gutierrez e Oliveira (2017) constataram que o rugby feminino possui menor quantidade de recursos, e que jogadoras sofrem críticas em razão das mudanças em seus corpos, aproximando-se do que é tido como masculino, ou seja, fugindo ao padrão de feminilidade esperado (GOELLNER, 2005).

Alguns autores (GOELLNER, 2005, 2007a, 2007b, 2013; SILVEIRA, 2013), defendem que não se deve utilizar argumentos biológicos para sustentar um afastamento das mulheres em determinadas modalidades esportivas. Ademais, propõem que não se fiscalize o corpo das atletas, objetivando evitar que sofram críticas por não se encaixarem no padrão construído de uma feminilidade padronizada.

Diante disso, a problemática pode ser resumida na seguinte questão: As desigualdades de gênero nos esportes têm bases biológicas ou são construídas? A hipótese é de que há um discurso - criado em um contexto de desejo de manutenção de poder masculino - que contribui para as desigualdades existentes no campo esportivo. Ressalte-se que para o desenvolvimento dessa temática foram essenciais alguns pesquisadores e pesquisadoras (BUTLER, 2017; BEAUVOIR, 1970; GOELLNER, 2005, 2007a, 2007b, 2013; CAMARGO; KESSLER, 2017; LIMA, 2018; COSTA; SANTOS, 2018; SILVEIRA, 2013; FOUCAULT, 1999, 1979, 2008).

De maneira específica, foi necessário compreender especificidades sobre o princípio da igualdade, revelando-se este um marco teórico, aliado às questões de gênero no contexto esportivo, além de se observar que há diversos conceitos construídos a partir de interesses na manutenção de um status de dominação e que ainda se refletem na atualidade (LAQUEUR, 1994; LIMA, 2018; GOELLNER, 2007a; MADERS; ANGELIN, 2010; MORENO, 2009 apud MONTEIRO; FORMENTIN, 2019).

Para atingir a proposta, na primeira seção investigou-se o princípio da igualdade, seus conceitos e possibilidades de um tratamento desigual que seja considerado justo, tendo como base, especialmente, as lições de Bobbio (1993). Apesar de serem possíveis abordagens desiguais, mas justas, a situação é bastante complexa nos esportes, compreendendo-se este como um mundo que, em alguns casos, se apoia em argumentos biológicos para fundamentar desigualdades injustas.

Posteriormente, analisaram-se a desigualdade de gênero e sexo biológico. Desse modo, Maders e Angelin (2010), Goellner (2007a; 2007b) e Silveira (2013) apontam estereótipos atrelados ao corpo e comportamento das mulheres que, constituídos com base em discursos marcados pela desigualdade de gênero e imbricados à Biologia, servem para recomendar condutas às mulheres. Esses discursos estereotipados são responsáveis por disseminar, manter e institucionalizar preconceitos quanto aos seus corpos e orientações quando "fogem" do "padrão" esperado da feminilidade (GOELLNER, 2005; BETTINE; GUTIERREZ; OLIVEIRA, 2017).

Essa realidade foi apontada, especificamente, quanto ao futebol, rugby, inclusive por meio de estudos de caso (SOUSA JÚNIOR, 2013; WRIGHT; CLARKE, 1999). Quanto à Fórmula 1, consideraram-se as lições de Foucault $(1999,1979,2008)$ e de autores que dissertam sobre ele ou acerca da Análise de Discurso (IÑIGUEZ, 2004a, 2004b; ORLANDINI, 2003a, 2003b; JAEGER; GOELLNER, 2011; WRIGHT; CLARKE, 1999; MACHADO, 2007; MORAES E SILVA, 2012; DUARTE, 2008; GIACOMONI; VARGAS, 2010). Percebeu-se o contexto de machismo que moldava discursos excludentes, e que por meio do poder disciplinar, verificável nos discursos, há delimitação de espaços para a manutenção da hegemonia masculina. A partir de Butler (2017), abordou-se sobre a reprodução de poder nos discursos.

Utilizou-se o método dedutivo, partindo-se da premissa de que a participação feminina nos esportes é desigual, encontrando diversas barreiras em razão do gênero, concluindo-se ser necessária a compreensão 
das construções que moldam essa realidade para que se possa alterá-la. Além disso, realizaram-se pesquisas bibliográficas e eletrônicas em teses, livros, dissertações, periódicos e notícias. Sobre estas, recorreu-se à Análise de Discurso (AD) baseada em Foucault (2008), para compreender as condições de produção e relações de poder de discursos que tentavam justificar a incapacidade física das mulheres para a prática de Fórmula 1.

\section{UM TRATAMENTO DESIGUAL É SEMPRE BEM-VINDO?}

O presente trabalho aborda discriminações decorrentes do gênero, que implica, entre outras consequências negativas, à falta de ocupação de espaços por indivíduos - pertencentes a uma minoria política ${ }^{1}$ - e excluídos em razão de marcadores ${ }^{2}$ de gênero. Um reflexo dessa situação é a desigualdade na participação feminina nos esportes que, conforme se verifica em alguns autores (GOELLNER, 2005; 2007a, 2007b, SILVEIRA, 2013), associa-se a um contexto marcado por atribuições de lugares específicos às mulheres.

Segundo Mello (2002, p. 17), para que uma discriminação seja compatível com a igualdade deve existir "um vínculo de correlação lógica entre a peculiaridade diferencial acolhida por residente no objeto, e a desigualdade de tratamento em função dela conferida, desde que tal correlação não seja incompatível com interesses prestigiados na Constituição". Já $\operatorname{Rios}^{3}(2010$, p. 696) define a discriminação como "a reprovação jurídica das violações do princípio isonômico, atentando para os prejuízos experimentados pelos destinatários de tratamentos desiguais".

Bobbio (1993) defende que há uma dificuldade em se definir o princípio da igualdade, haja vista sua indeterminação. Assim, não haveria sentido afirmar que dois entes são iguais se não for determinada a igualdade entre quem, e em que. Comparando igualdade à liberdade, afirma que enquanto esta se relaciona a uma qualidade pessoal, aquela seria uma espécie de relação. Desse modo, traça uma correlação entre esses princípios. Aduz que "a liberdade é uma qualidade de um ente, e a liberdade um modo de estabelecer um determinado tipo de relação entre os entes de uma totalidade, apesar de que a única característica comum desses entes é o direito de ser igualmente livres" (p. 56). ${ }^{4}$

Avaliando a relação entre igualdade e justiça, Bobbio (1993) levanta o que seria uma igualdade justa e injusta, ou seja, a que seria, ou não, almejada. Nesse sentido, remete o leitor aos critérios de justiça. Por meio deles é possível "estabelecer situação por situação em que duas coisas ou duas pessoas devam ser iguais com o objetivo de que a igualdade entre elas possa ser considerada justa" (p. 62). ${ }^{5}$ Explica também que a igualdade diante da lei, tida como um princípio comum e genérico, normalmente é interpretada como a vedação a uma discriminação arbitrária, ou seja, que não possui justificativas, e em razão disso, injusta (BOBBIO, 1993).

Bobbio (1993) menciona também um conceito sobre igualdade de oportunidades, ou de pontos de partida, que se verifica em uma competição por determinado objetivo que só poderá ser alcançado por uma pessoa. Exemplifica mediante um jogo de xadrez, em que haveria esse tipo de igualdade se todos possuíssem a mesma quantidade e espécie de peças. A noção, contudo, vai além: a fim de igualar indivíduos que são desiguais desde que nasceram, podem ser necessárias transformações, como desfavorecer os mais acomodados e beneficiar os despossuídos. Isso ocorreria por meio da inclusão de discriminações, como acontece em determinadas competições vinculadas ao esporte. Dessa maneira, uma desigualdade

\footnotetext{
${ }^{1}$ Expressão defendida por Tiburi (2018). Segundo Costa e Zaidan Filho (2019, p. 38), "gênero, sexualidade, raça e etnia compõem o conjunto das chamadas minorias, valores estes que foram construídos ao longo da história, como antagônicos a valores expressos como superiores e desejáveis. Assim, a construção hegemônica do masculino é feita em oposição à constituição inferior do feminino [...]".

2 Termo mencionado na obra de Schwarcz (2019), quando remete aos Marcadores Sociais da Diferença definidos pelo Núcleo de Estudos sobre Marcadores Sociais da Diferença da Universidade de São Paulo (USP).

3 Este autor aponta que "a discriminação aqui é visualizada através de uma perspectiva mais substantiva que formal: importa enfrentar a desigualdade nociva, pois nem sempre a adoção de tratamentos distintos revela-se maléfica, sendo mesmo tantas vezes exigida, até em virtude da dimensão material do princípio da igualdade" (RIOS, 2010, p. 696).

4 Tradução de Tayana Roberta Muniz Caldonazzo.

5 Tradução de Tayana Roberta Muniz Caldonazzo.
} 
se transmuta em meio de se obter igualdade, pois corrige a diferença anterior. Há, assim, a colocação dos desiguais no mesmo nível.

Conclui-se que o ponto comum entre as doutrinas igualitárias é a busca por igualdade substancial. A doutrina do igualitarismo, especificamente, busca a igualdade de todos no que se refere a todos os aspectos. Tendo ciência, porém, de ser este um objetivo utópico, busca-se a igualdade para a maioria das pessoas entre a quantidade máxima de aspectos (BOBBIO, 1993).

Analisar os direitos fundamentais da população feminina envolve o debate sobre igualdade, a fim de que se torne clara a possibilidade de um tratamento desigual como justo. Há desigualdades viciadas, mal fundamentadas e consequentemente injustas, pois baseadas em atribuições de gênero. Assim, argumentar que a mulher não deveria competir em uma modalidade esportiva, pois feriria sua feminilidade (GOELLNER, 2005; 2007a, SANTANA; SILVA, 2015; NINA, 2019), é um exemplo de tratamento desigual viciado, fundamentado em preconceitos reflexos da desigualdade de gênero, que deve ser questionado e visto com cautela, na medida em que fere o princípio da igualdade substancial (BOBBIO, 1993).

\section{LIMITAÇÕES ESTEREOTIPADAS: \\ OS PROBLEMAS DE UM DISCURSO DESIGUAL EM GÊNERO NO ESPORTE}

Em que pesem, conforme apontam alguns autores (BOBBIO, 1993; SILVEIRA, 2013; GOELLNER, 2007a, MONTEIRO; FORMENTIN, 2019; NINA, 2019), tratamentos desiguais sejam válidos e necessários para enfrentar injustiças, nos esportes é comum encontrar discursos que defendem ser a mulher inapta a participar de determinada modalidade com base em argumentos que não se sustentam, ou ainda, encontrar recomendações em relação às suas vidas e seus corpos. ${ }^{6}$

Segundo Flores (2010), adotar uma perspectiva de gênero permite compreender as relações de poder existentes, bem como aferir que as dominações não possuem qualquer origem biológica ou natural. Também nesse sentido, Maders e Angelin ressaltam:. "As relações de gênero foram se firmando ao longo da história, configurando-se como construções culturais de identidades masculinas e femininas, envolvendo relações de poder e impondo comportamentos aos homens e às mulheres" (2010, p. 93).

De acordo com Goellner (2007a), a obra de Joan Scott (1989) intitulada "Gender: a useful category of historical analysis", além de ser uma referência para os estudos de gênero, contribui para o campo da historiografia contemporânea, na medida em que realçou "a necessidade de se analisar o caráter relacional existente entre os sexos" (GOELLNER, 2007a, p. 176). Torrão Filho (2005, p. 129) explica que na visão de Scott, a conceituação de gênero foi gerada "para opor-se a um determinismo biológico nas relações entre os sexos, dando- Ihes um caráter fundamentalmente social". A nova perspectiva de gênero, adotada a partir de Scott, "rompe significativamente com a noção de que exista um único jeito masculino ou feminino de ser" (GOELLNER, 2005, p. 148). De fato, gênero, para Joan Scott (1989), divide-se em partes e subpartes. Compreende-o como "um elemento constitutivo de relações sociais baseado nas diferenças percebidas entre os sexos, e o gênero é uma forma primeira de significar as relações de poder" (p. 21).

A própria noção de sexo foi construída historicamente (LAQUEUR, 1994). Foi na segunda metade do século 20 que se teve uma necessidade "de se instituir uma diferenciação sexual biológica, dualista e estanque entre corpos que são percebidos de maneira radicalmente oposta" (BENTO, 2006 apud LIMA, 2018, p. 63). Pensava-se que homens e mulheres teriam a mesma genitália, no entanto nelas os órgãos estariam dentro de seus corpos. Assim, seriam homens com uma configuração imperfeita de suas genitálias (LAQUEUR, 1994 apud LIMA, 2018).

No final do século 18 defendia-se que distinções físicas serviam para qualificar alguns indivíduos (SCOTT, 2005). Laqueur (1994 apud LIMA, 2018), tendo em vista a Revolução Francesa e os objetivos democrático-bur-

\footnotetext{
6 Cumpre fazer uma ressalva: as questões atreladas a gênero e sua violência refletem-se na vida de diversos indivíduos, não se restringindo às mulheres. Tendo em vista, no entanto, a necessidade de um recorte, a pesquisa restringe-se à situação das mulheres e discriminação que sofrem em razão de seu gênero no mundo esportivo. Outros enfoques, porém, são imprescindíveis e carecem de novos aprofundamentos. Devide et al. (2011, p. 99) destacam que "o foco dos estudos de gênero na EF [educação física] ainda mantém associação com os estudos das mulheres".
} 
gueses, considera que o cenário influenciou a criação de um discurso que diferenciava e hierarquizava homens e mulheres, a fim de manter a dominação masculina na esfera pública.

Assim, a diferenciação entre homens e mulheres a partir de características físicas, como algo relevante, é uma situação construída e voltada à manutenção de poder masculino: para Goellner (2013), as diferenças significativas não são determinadas pela Biologia, e sim decorrentes de construções sociais e culturais. ${ }^{7}$ Segundo Rios (2010), a lógica binária da atualidade traz consequências negativas para o direito das mulheres, na medida em que esse binarismo "reforça dinâmicas históricas de subordinação feminina, reproduzindo situações e ideologias onde às mulheres são reservados o domínio do lar e um papel secundário na vida pública, social e econômica" (p. 708). O binarismo de gênero, na visão do autor, "tende a compactuar com diferencialismos sexuais que diminuem o espaço de construção de novas relações entre homens e mulheres, capazes de romper com privilégios e dominação masculinos" (p. 708).

Goellner (2007a) aponta que determinadas marcas culturais determinam o que é típico do feminino e do masculino, ${ }^{8}$ e nos esportes ocorre situação similar: musculatura, roupas, acessórios, trazem sentidos que, nesta sociedade e tempo, relacionam-se ao masculino e ao feminino, de modo a ensejar, muitas vezes, a colocação de homens e mulheres em distintas práticas esportivas.

Essas marcas culturais geram a crença de que há características vinculadas, automaticamente, ao sexo biológico (GOELLNER, 2007a), acarretando em "traços de caráter, o comportamento, as funções sociais, os espaços de pertencimento e as possibilidades de movimentação para eles e para elas" (p. 184).

Segundo a lógica de que o critério para definir indivíduos é seu corpo, "nada mais 'natural' que recomendar aos homens e mulheres diferentes possibilidades de movimentação" (GOELLNER, 2007a, p. 184). Assim, para indivíduos do sexo masculino são aceitáveis a força, desafio, aventura, etc. Já para o sexo feminino tudo deve ser comedido. Até poderiam participar do campo esportivo, desde que não deixassem seus atributos femininos de lado, como beleza, delicadeza, entre outros (GOELLNER, 2007a). Essas alegações funcionam "como mecanismos de exclusão e inclusão em diferentes modalidades esportivas, posicionam as mulheres, demarcam seus espaços de sociabilidade, pois insistem em afirmar que determinadas atividades não são apropriadas aos seus corpos" (p. 185), vistos como mais frágeis se comparados aos dos homens (GOELLNER, 2007a).

A percepção de que os discursos são perpassados por poder foi importante para deixar de legitimar argumentos biológicos que justificavam desigualdades entre os indivíduos (GOELLNER, 2007a). Esse poder relaciona-se, de forma exemplificativa, à possibilidade de apontar em quais modalidades esportivas os homens e mulheres seriam aceitos, ou ainda "de classificar níveis de performance possíveis de serem desenvolvidos, de inferir as habilidades e capacidades físicas de cada um, de nomear aquelas/aqueles que correspondem a essas expectativas ou, ao contrário, quem delas escapa" (GOELLNER, 2007a, p. 188).

Até que ponto a separação de implementos, de tempos, de pesos, de provas ou quaisquer outros fatores que se apresentam no universo esportivo não são estratégias edificadas para justificar o domínio e a proeminência do masculino, via força, virilidade, eficácia, combatividade, poder, todos valores instituídos e legitimados? Se viabilizarmos a implosão do modelo binário "bio", modelos de gênero naturalizados, daremos possibilidade às desreferencializações e desgenerificações a corpos outros que habitam os esportes, desestabilizando prerrogativas instituídas (CAMARGO; KESSLER, 2017, p. 218).

Assim, não é o corpo do indivíduo que determinará a modalidade esportiva ideal para uma mulher, ou se ela tem capacidade de treinar uma equipe; "é a discursividade construída sobre a funcionalidade do corpo e sua correlata associação aos processos de socialização que provoca e constrói tais demarcações" (GOELLNER, 2007a, p. 189). Costa e Santos (2018) entendem ser importante ressignificar e reposicionar "as distinções

Utilizar a Biologia como justificativa para uma suposta inferioridade feminina não é um movimento inédito: Beauvoir (1970) aponta que os antifeministas, objetivando demonstrar a inferioridade das mulheres, já recorreram "não somente para a religião, a filosofia e a teologia, como no passado, mas ainda para a ciência: biologia, psicologia experimental, etc".

8 Desse modo, a partir de uma perspectiva de gênero pode-se compreender que gestualidades, performances e sexualidade, por exemplo, foram construídos na História. Ou seja, em diferentes períodos e contextos determinados atributos são vistos como típicos de homens e/ ou de mulheres, havendo indicações sobre o que é masculino e feminino (GOELLNER, 2007a). 
entre os sexos, remodelando conceitos biologicamente postos (macho e fêmea) em homens e mulheres como seres sociais, que têm suas desigualdades marcadas por fatores sociais e não por conta de sua origem biológica" (p. 142).

Há diferenças físicas entre os atletas que poderiam gerar vantagens injustas caso competissem em conjunto. $\mathrm{O}$ que se critica, no entanto, é um discurso que delimita espaços às mulheres, justificado por uma suposta inaptidão feminina para determinadas práticas. Tendo por base especialmente Goellner (2007a, 2007b) e Camargo e Kessler (2017), observou-se que são discursos influenciados por estereótipos destinados a manter uma ordem de dominação masculina.

\section{BARREIRAS NA PARTICIPAÇÃO FEMININA NO ESPORTE}

Diversos fatores influenciam para uma participação desigual das mulheres nos esportes: há interferência de um sistema heteronormativo que dita regras sobre como deve ser o corpo feminino, estereótipos sobre a fragilidade das mulheres, noção de que certos atributos atrapalham a feminilidade, além de o patrocínio ser diferenciado às mulheres (GOELLNER, 2005, 2007a, 2007b, SILVEIRA, 2013; SILVA; NAZÁRIO, 2018; SANTANA; SILVA, 2015; BETTINE; GUTIERREZ; OLIVEIRA, 2017; NUNES; SILVA, 2019).

Ressalte-se que a desigualdade é histórica: o surgimento do esporte moderno tem seu berço na Inglaterra, século 19, sofrendo influências da sociedade industrial (SILVEIRA, 2013), e possui "uma dinâmica quase que exclusivamente determinada pelos membros do sexo masculino" (p. 5). As mulheres conseguiram maiores oportunidades nesse espaço a partir do início do século 20 (GOELLNER, 2005). Nesse período ocupavam um papel secundário, como torcedoras, localizadas à margem (CAMARGO; KESSLER, 2017). No atletismo criou-se uma categoria feminina somente em 1984, observando-se que foi no início dos anos 70 que se permitiu às mulheres a participação nessa modalidade. Outras provas, como lançamento de martelo, salto com vara, corrida com obstáculos, eram praticadas exclusivamente por homens por diversos anos (SILVEIRA, 2013). De fato, nem todos os esportes eram indicados às mulheres, a exemplo do futebol, visto como excessivamente violento (GOELLNER, 2005).

Ainda que as mulheres pudessem competir em alguns eventos vinculados ao esporte, receava-se a desmoralização feminina, na medida em que mostravam seus corpos, situação que perturbava as famílias, em especial as pertencentes à elite. Certos elementos, como a prática do esporte, atenção à aparência, visibilidade de corpos e uso de estética (GOELLNER, 2005) "eram identificados como impulsionadores da modernização da mulher e da sua auto-afirmação na sociedade e, pelo seu contrário, como de natureza vulgar que a aproximava do universo da desonra e da prostituição" (p. 145).

Uma situação marcante no caminho da inclusão feminina nos esportes foi sua participação nos Jogos Olímpicos Modernos, na medida em que trouxe visibilidade às atletas. Alguns indivíduos, no entanto, ainda se posicionaram de forma contrária à integração, preferindo que as mulheres somente assistissem aos jogos. Entre outros argumentos, alegava-se que o esforço, as emoções fortes, a leveza de roupas, os músculos desenvolvidos, a seminudez, acabariam por perturbar a imagem ideal feminina (GOELLNER, 2005), notando-se um argumento influenciado por atribuições de gênero. Ademais, eventuais participações "poderiam desestabilizar a estruturação de um espaço de sociabilidade criado e mantido sob domínio masculino, cuja justificativa para sua consolidação, assentada na biologia do corpo e do sexo, deveria atestar a superioridade deles em relação a elas" (p. 144).

Em outras palavras, a possibilidade de vitórias alcançadas por mulheres atletas existe há pouco tempo. Os esportes masculinos receberam, durante a História, maiores incentivos que os femininos, haja vista os preconceitos enfrentados pelas mulheres quanto a sua participação nas modalidades de alto rendimento ou em momentos de lazer, impedindo-se uma prática igualitária (SANTANA; SILVA, 2015). Diante disso, constata-se a desigualdade de oportunidades, tratada na primeira seção a partir dos ensinamentos de Bobbio (1993).

Entre as barreiras a serem quebradas por meio de uma perspectiva de gênero, insere-se a desnaturalização da fiscalização do corpo feminino. Ou seja, aquelas mulheres que não se encaixam em padrões corporais são alvo de preconceito e questionamentos, observando-se os reflexos de um sistema desigual e heteronormativo (GOELLNER, 2005; SILVA; NAZÁRIO, 2018; BETTINE; GUTIERREZ; OLIVEIRA, 2017). 
É comum observar estranhamentos quanto ao corpo feminino que passa por transformações em razão da prática de atividades físicas (GOELLNER, 2005), casos em que "são atribuídas características viris que não apenas questionam sua feminilidade, mas também colocam em dúvida a autenticidade de seu sexo" (p. 148). As atletas são indagadas sobre suas identidades de gênero e orientações sexuais (SILVA; NAZÁRIO, 2018), pois "um corpo feminino robusto, forjado no e pelo esporte, manifesta atributos como força, agressividade e habilidade técnica - elementos culturalmente entendidos como tipicamente masculinos" (p. 2). Em razão desse cenário, a sexualidade de jogadoras de futebol, muitas vezes, é investigada, como se fosse aceitável essa espécie de fiscalização (GOELLNER, 2005).

Há um padrão de performance nos esportes, acreditando-se que o marco de um bom desempenho é aquele alcançado por homens, e as mulheres que tentam atingi-lo são vistas como distantes do parâmetro esperado, podendo ser alvos de preconceitos e questionadas quanto aos seus corpos e em relação a sua sexualidade (CAMARGO; KESSLER, 2017).

Ocorre que a mulher que apresenta um corpo considerado viril perpassa suas experiências a partir de um enfoque diverso do considerado "padrão", ou seja, o da heterossexualidade (GOELLNER, 2005). De fato, Moreira (2017) aduz que a heterossexualidade expressa o que é considerado normal. "É sobre a natureza biológica das mulheres que se constrói o mito da fragilidade feminina e é nesse processo de proibições e recomendações para os sexos que o território do esporte se constitui" (SILVEIRA, 2013, p. 14). Algumas atletas desorganizam atribuições destinadas aos sexos na medida em que transpõem barreiras criadas socialmente, a partir de músculos desenvolvidos e força, permitindo-se que expressem novas formas de feminilidades, razão pela qual os esportes também podem ser meios de subverter normas de gênero (SILVEIRA, 2013).

Jaeger e Goellner (2011) exemplificam essa situação em estudo publicado sobre fisiculturismo. Após determinação do Body Building (IFBB), ${ }^{9}$ em 2005, para que as atletas mulheres não desenvolvessem músculos volumosos, pode-se concluir que um corpo que ultrapasse esse limite perturbaria a feminilidade. Além disso, a declaração "sugere que as atletas [...] colocavam em dúvida uma 'imagem ideal de ser mulher', ao mesmo tempo em que desestabilizavam um terreno criado e mantido sob o domínio masculino, cuja existência justifica-se pela anatomia do corpo e do sexo" (p. 961). Em consequência, as atletas tomaram diversas medidas relacionadas à aparência para mostrarem sua feminilidade que, criada por meio de um discurso, normatiza o que define uma mulher. Assim, se os músculos geram alguma dúvida, utilizam-se outras maneiras de evidenciar a feminilidade (JAEGER; GOELLNER, 2011).

Interessa observar os reflexos desse sistema excludente em modalidades específicas - Fórmula 1, futebol e rugby, escolhidas a título exemplificativo a fim de ilustrar as desigualdades de gênero neles presentes.

\subsection{Fórmula 1}

Não é comum encontrar mulheres pilotas de Fórmula $1,^{10}$ e para Monteiro e Formentin (2019), isso ocorre justamente por ser uma modalidade a motor, relacionada, de maneira cultural, ao universo masculino. Estes autores estudaram a representação da mulher na editoria de Fórmula 1 do Globoesporte.com, estabelecendo enfoque nas representações midiáticas das pilotas que praticam a modalidade.

Na conclusão da pesquisa, notaram a presença de estereótipos em imagens e textos. Os jornalistas "utilizam palavras associadas ao caos, polêmicas e fenômenos, sugeriram a falta de capacidade das mulheres [...]. Há ainda um longo caminho para percorrer para que a mulher seja apresentada sem marcas culturais que a caracterizem como indefesa" (MONTEIRO; FORMENTIN, 2019, p. 232).

Chamou atenção a fala de Carmen Jordá, representante da Comissão de Mulheres da Federação Internacional de Automobilismo (FIA), que já ocupou a posição de pilota de testes da categoria (MONTEIRO; FORMENTIN, 2019). Jordá declarou que haveria uma barreira por motivos físicos para a participação de mulheres nas modalidades Fórmula 1 e Fórmula 2, e esta seria a razão pela qual não são comumente vistas atuando nesses campeonatos (JORDÁ apud ESFORÇO FíSICO..., 2018). Os autores buscaram demonstrar que o repórter,

\footnotetext{
9 Trata-se de uma instituição relacionada ao fisiculturismo, atuante em âmbito mundial (JAEGER; GOELLNER, 2011).

${ }^{10}$ Segundo Nina (2019), há poucas mulheres no automobilismo.
} 
ao tratar dessa afirmação, julgou o desenvolvimento de Jordá, além de ter depreciado sua opinião. Quanto à afirmação da atleta, apresentaram um contraponto: em notícia referente à contratação de Tatiana Calderón como pilota de testes da Sauber, ${ }^{11}$ Fred Vasseur - chefe da equipe responsável por sua admissão (MONTEIRO; FORMENTIN, 2019) - enfatizou que certas características podem ser desenvolvidas durante o treino (VASSEUR apud COLOMBIANA TATIANA..., 2018).

A dúvida sobre a capacidade feminina para competir na Fórmula 1 por razões biológicas também aparece em outro momento. Em matéria intitulada "Por que não há mulheres na Fórmula 1: capacidade ou oportunidade?", Roberta Nina destaca que Helmut Marko, consultor da equipe RBR, afirmou: "A fórmula 1 é muito física para as mulheres" (MARKO apud NINA, 2019), de modo que não conseguiriam competir nesta modalidade porque são necessárias exigências físicas não características da natureza feminina. Segundo o consultor, em entrevista concedida ao jornal Kleine Zeitung (NINA, 2019), "se você está pilotando a $300 \mathrm{~km} / \mathrm{h}$ e tem uma luta roda a roda, então a brutalidade é parte disso, não sei se isso é da natureza feminina. Você tem de estar em forma na Fórmula 1 e precisa de uma força insana desde o ombro" (MARKO apud NINA, 2019).

A fim de extrair os sentidos desses discursos, utiliza-se a Análise de Discurso ${ }^{12},{ }^{13} \mathrm{com}$ base em Foucault (2008). Segundo Orlandini (2003a), os sentidos dependem não somente do que foi escrito ou dito, mas também do contexto, da ligação com o exterior. Assim, os dizeres [...] São efeitos de sentidos que são produzidos em condições determinadas e que estão de alguma forma presentes no modo como se diz" (p. 30). Nesse contexto, regras para formação discursiva, segundo Foucault $(2008$, p. 43), "são condições de existência (mas também de coexistência, de manutenção, de modificação e de desaparecimento) em uma dada repartição discursiva". Já o discurso é definível como

um conjunto de enunciados, ${ }^{14}$ na medida em que se apoiem na mesma formação discursiva; ele não forma uma unidade retórica ou formal, indefinidamente repetível e cujo aparecimento ou utilização poderíamos assinalar (e explicar, se for o caso) na história; é constituído de um número limitado de enunciados para os quais podemos definir um conjunto de condições de existência. O discurso, assim entendido, não é uma forma ideal e intemporal que teria, além do mais, uma história; o problema não consiste em saber como e por que ele pôde emergir e tomar corpo num determinado ponto do tempo; é, de parte a parte, histórico - fragmento de história, unidade e descontinuidade na própria história, que coloca o problema de seus próprios limites, de seus cortes, de suas transformações, dos modos específicos de sua temporalidade, e não de seu surgimento abrupto em meio às cumplicidades do tempo (FOUCAULT, 2008, p. 132-133).

\footnotetext{
${ }^{11}$ Trata-se de uma "categoria máxima do automobilismo mundial" (MONTEIRO; FORMENTIN, 2019, p. 222).

12 Não há somente uma definição para a Análise de Discurso (IÑIGUEZ, 2004b). O autor a explica "como uma perspectiva a partir da qual podemos analisar os processos sociais" (IÑIGUEZ, 2004a, p. 53). Além disso, "visa compreender como os objetos simbólicos produzem sentidos [...]. não estaciona na interpretação, trabalha seus limites, seus mecanismos, como parte dos processos de significação. Também não procura um sentido verdadeiro através de uma 'chave' de interpretação. [...] Não há uma verdade oculta atrás do texto. Há gestos e interpretação que o constituem e que o analisa, com seu dispositivo, deve ser capaz de compreender" (ORLANDINI, 2003a, p. 26). Segundo Orlandini (2003b, p. 6), "a análise de discurso reúne, deslocando, língua-sujeito-história, construindo um objeto próprio, o discurso, e um campo teórico específico".

13 Para tanto, observaram-se as regras propostas por Iñiguez (2004b). O primeiro passo é escolher o processo a ser objeto de estudo. Para tanto, "o estabelecimento do foco de análise implica perguntar que relações sociais mantidas e divulgadas através da linguagem estamos querendo explicar" (p. 132). Este trabalho estabelece como foco as relações desiguais de gênero estabelecidas por meio da linguagem. Para Iñiguez (2004b), a relação social estudada é controlada e interferida pela linguagem. Após esse passo metodológico, seria necessário definir um material importante para o estudo. Escolheram-se discursos perpassados por machismo na Fórmula 1, considerados representativos por participarem de um contexto maior, ou seja, da desigualdade de gênero e de suas implicações. Além disso, possuem os efeitos discursivos porque trazem "certos significados, certos sentidos, certos olhares, certas ordens do mundo ou de uma parcela do mundo" ( $p$. 138). Por fim, realizou-se a análise, observando-se os atos de fala - que trazem efeitos relevantes, na medida em que as afirmações ensejam uma sanção, consistente na impossibilidade de participação feminina na categoria, - bem como a retórica - (IÑIGUEZ, 2004b), que para Biling (1987), citado por Iñiguez (2004b, p. 143), "é [...] útil para analisar a credibilidade e a legitimidade que um texto transmite" (p. 143), haja vista que se considerou a importância de não disseminar discursos marcados pelo machismo para que não se crie um cenário de verdade (IÑIGUEZ, 2004b).

${ }_{14}$ Trata-se de "uma função que possibilita que um conjunto de signos, formando unidade lógica ou gramatical, se relacione com um domínio de objetos, receba um sujeito possível, coordene-se com outros enunciados e apareça como um objeto, isto é, como materialidade repetível. É pelo enunciado que se tem o modo como existem essas unidades de signos. Ele lhes dá as modalidades particulares de existência, estipula as condições de existência dos discursos. Descrever um enunciado é descrever uma função enunciativa que é uma condição de existência" (MACHADO, 2007, p. 109).
} 
Foucault entende que o discurso é uma prática social, ${ }^{15}$ o que permite que se compreendam as condições de produção, ou seja, a formação discursiva (IÑIGUEZ, 2004a). Por sua vez, práticas discursivas são "regras anônimas, históricas, sempre determinadas no tempo e no espaço, que definiram, em uma dada época e para uma determinada área social, econômica, geográfica ou linguística, as condições de exercício da função enunciativa" (FOUCAULT, 2008, p. 133). Desse modo, pode-se afirmar que "a AD é uma prática [...] que não só desmascara ou identifica outras práticas discursivas, como também - e sobretudo - abre todo um caminho para sua transformação" (IÑIGUEZ, 2004b, p. 147).

Dito de outro modo, há relações de poder e de saber que, juntos, influenciarão sobre o que os indivíduos podem dizer, a forma como o fazem e em quais condições poderão dizer, bem como quem dirá e em quais circunstâncias (FOUCAULT, 2005, 1974 apud JAEGER; GOELLNER, 2011; WRIGHT; CLARKE, 1999), ${ }^{16}$ havendo reflexos de relações de poder expressas, por exemplo, em falas (JAEGER; GOELLNER, 2011). ${ }^{17}$

Os discursos de Jordá, Marko e Vasseur foram produzidos em um contexto desigual de gênero: um ambiente constituído pelo masculino e com tentativas evidentes de manutenção dessa dominação. Para tanto, entre outros movimentos, fazem uso de diferenças biológicas para justificar o impedimento da participação feminina em determinadas modalidades, demonstrando-se um caráter excludente e decorrente de uma construção discursiva (CAMARGO; KESSLER, 2017; SILVEIRA, 2013; GOELLNER, 2005, 2007a), o que viola a igualdade substancial (BOBBIO, 1993).

Em razão desse contexto, ressalta-se o problema ${ }^{18}$ de declarações que contestam a capacidade física de mulheres, na medida em que podem contribuir para a disseminação de atribuições que procurem ditar qual o lugar a ser por elas ocupado. A falta de capacidade física de mulheres para atuarem na Fórmula 1 é uma crença a ser vista com desconfiança, ${ }^{19}$ haja vista toda a construção que cerca essa espécie de raciocínio.

Como contraponto, além das discussões já expostas neste trabalho, menciona-se Vasseur (apud COLOMBIANA TATIANA..., 2018), que acredita na possibilidade do desenvolvimento de certas características por meio do treino.

Nesse sentido, a cultura influencia quais padrões são masculinos e femininos que, por sua vez, dialogam com as estruturas de poder - especialmente os decorrentes da desigualdade de gênero - auxiliando na manutenção de espaços a serem ocupados por homens e mulheres, deixando-as, muitas vezes, à margem, ou restringidas ao ambiente doméstico (GOELLNER, 2007a; MADERS; ANGELIN, 2010; RIOS, 2010). Assim, deve-se olhar com cautela para restrições e desigualdades injustificadas, que não observam a noção de igualdade substancial (BOBBIO, 1993), na medida em que trazem injustiças.

Moraes e Silva (2012) ensina que Foucault, em Arqueologia do Saber, ${ }^{20}$ estudava essencialmente o discurso. Posteriormente, em sua genealogia ${ }^{21}$ também pensou nas formas de funcionamento das relações de poder. Duarte (2008) ensina que na fase inicial da geneaologia, Foucault trabalhou com micropoderes disciplinares relacionados ao controle do corpo individual, e suas emergências, no século 17 , se deram ao mesmo

\footnotetext{
15 Também nesse sentido, Giacomomi e Vargas (2010). Por ser uma prática social, "incorpora elementos constitutivos que não são puramente linguísticos já que esses são os elementos que, condicionados por um contexto histórico particular e um inventário de regras socialmente elaboradas, constituem os objetos sobre os quais falam" (IÑIGUEZ, 2004a, p. 98-99).

${ }_{16}$ Jaeger e Goellner (2011), Wright e Clarke (1999) referem-se à Arqueologia do Saber.

17 Orlandini (2003a), tratando das condições de produção para a criação de discursos, remete, entre outros fatores, à relação de forças. De modo que, "o lugar a partir do qual o sujeito é constitutivo do que diz [...]. Como nossa sociedade é constituída por relações hierarquizadas, são relações de força, sustentadas no poder desses diferentes lugares, que se fazem valer na 'comunicação'” (p. 39-40). Para Jaeger e Goellner (2011), há relações de poder imbricadas nos discursos.

${ }_{18}$ Monteiro e Formentin (2019, p. 222) argumentam que "a conservação de concepções semelhantes à de Carmen Jordá, de que a mulher não é capaz ou não tem físico para disputar lado a lado com homens, é o que contribui para a representação de estereótipos nos meios de comunicação". Buitoni (2009, p. 212) e Moreno (2009), citados por Monteiro e Formentin (2019), argumentam, respectivamente, que a mídia brasileira tem papel importante sobre a permanência de padrões, e que os estereótipos podem contribuir para a criação de dúvidas sobre a capacidade dos indivíduos.

19 "As justificações biológicas que fundamentam as recomendações diferenciadas para mulheres e homens no campo do esporte merecem, no mínimo, serem observadas com desconfiança" (GOELLNER, 2007b, p. 5).

20 "A arqueologia é o método próprio à análise da discursividade local" (FOUCAULT, 1979, p. 172).

21 "A genealogia é a tática que, a partir da discursividade local assim descrita, ativa os saberes libertos da sujeição que emergem desta discursividade" (FOUCAULT, 1979, p. 172).
} 
tempo que nasciam instituições como escolas, hospitais, entre outros. Já no final de sua geneaologia os micropoderes se relacionavam ao biopoder e biopolítica.

Interessa a esta pesquisa o início de sua genealogia, pensando-se nos conceitos de disciplina e poder disciplinar, e especificamente, na lógica excludente para obter dominação. ${ }^{22}$ As problemáticas da "Sociedade Disciplinar" são investigadas em Foucault (2005). ${ }^{23}$ Tratou-se de um contexto dos séculos 17 e 18, em que se buscava gerenciar a sociedade por meio de técnicas. Para tanto, o regime do poder disciplinar criou conhecimentos que contribuiriam para adequar o comportamento dos indivíduos, repercutindo em espaços para vigia, controle e disciplina, consistentes na escola, hospital, sociedade (SOUSA; MENESES, 2010). Desse modo, observa-se que havia meios de controlar os corpos.

O poder disciplinar não pertencia mais à figura de um soberano, na medida em que se espalhou pela sociedade, e seu exercício dava-se por meio de micropoderes ou micropolítica. Direcionava-se aos indivíduos de maneira estratégica para obtenção de maior intensidade, almejando o adestramento e docilização. ${ }^{24}$ Havia, ainda, instituições disciplinares, direcionadas aos excluídos socialmente (SOUSA; MENESES, 2010). Já as disciplinas são "métodos que permitem o controle minucioso das operações do corpo, que realizam a sujeição constante de suas forças e Ihes impõem uma relação docilidade-utilidade" (FOUCAULT, 1999, p. 118), constituindo-se em estratégias para dominar (FOUCAULT, 1999). Para Sousa e Meneses (2010, p. 25), "a disciplina passou a controlar os indivíduos estabelecendo relações de poder reguladas pelas normas".

A disciplina organizava pessoas em diferentes espaços, utilizando-se da cerca, como o que ocorria em colégios e quartéis, ou o encarceramento dos excluídos da sociedade; dos aparelhos disciplinares, agindo por meio do quadriculamento, que estabelecia lugares específicos aos indivíduos, entre outros (FOUCAULT, 1999).

O poder disciplinar é [...] um poder que, em vez de se apropriar e de retirar, tem como função maior "adestrar"; ou sem dúvida adestrar para retirar e se apropriar ainda mais e melhor. Ele não amarra as forças para reduzi-las; procura ligá-las para multiplicá-las e utilizá-las num todo. Em vez de dobrar uniformemente e por massa tudo o que lhe está submetido, separa, analisa, diferencia, leva seus processos de decomposição até às singularidades necessárias e suficientes. "Adestra" as multidões confusas, móveis, inúteis de corpos e forças para uma multiplicidade de elementos individuais. [...] A disciplina "fabrica" indivíduos; ela é a técnica específica de um poder que toma os indivíduos ao mesmo tempo como objetos e como instrumentos de seu exercício (FOUCAULT, 1999, p. 143).

Em outras palavras, o poder disciplinar usava da técnica de organização de corpos, a fim de realizar controle e vigilância, com o objetivo de alcançar determinados fins: que os indivíduos permanecessem dóceis, adestrados e que o cenário contribuísse para que o poder possuísse maior intensidade. A organização fez uso de técnicas, como instituições disciplinares, com viés excludente. Utilizando-se dessa lógica para as desigualdades apontadas no presente trabalho, compreende-se que ao fazer uso do discurso para determinar que atletas participem, ou não, de determinados espaços esportivos, incide uma vigilância e controle para que o esporte continue sob o domínio masculino.

Butler (2017) defende existir um poder externo aos indivíduos que, se lido a partir de Foucault, influencia para a formação do sujeito. Desse modo, haverá interiorização. ${ }^{25}$ Ainda afirma que "para que as condições do poder persistam, elas devem ser reiteradas; o sujeito é justamente o local de tal reiteração, uma repetição que

\footnotetext{
22 Biopoder e biopolítica, por sua vez, relacionam-se a um poder disciplinador proveniente do Estado, no sentido de controlar a população de diversas maneiras (DUARTE, 2008). As desigualdades e injustiças aqui investigadas relacionam-se ao machismo presente na sociedade, chegando também nos esportes. Não se trata, porém, de algo criado pelo Estado para controle da vida dos indivíduos; apenas gera reflexos na máquina estatal - assim como em outras esferas sociais.

${ }^{23} \mathrm{O}$ autor refere-se à obra Vigiar e Punir: nascimento da prisão.

24 "É dócil um corpo que pode ser submetido, que pode ser utilizado, que pode ser transformado e aperfeiçoado" (FOUCAULT, 1999, p. 118). "A disciplina fabrica [...] corpos submissos e exercitados, corpos 'dóceis'”' (FOUCAULT, 1999, p. 119).

${ }^{25}$ Para Butler (2017), a interiorização ocorre em razão da força do poder sobre os indivíduos. "O que essa descrição não diz, no entanto, é que 'nós' que aceitamos tais termos somos fundamentalmente dependentes deles para 'nossa' existência. [...] A sujeição consiste precisamente nessa dependência fundamental de um discurso que nunca escolhemos, mas que, paradoxalmente, inicia e sustenta nossa ação. 'Sujeição' significa tanto o processo de se tornar subordinado pelo poder quanto o processo de se tornar um sujeito" (p.10).
} 
nunca é meramente mecânica" (p. 24). A partir disso, observa-se como o poder advindo da hierarquia de gênero é interiorizado nos sujeitos, sobrevivendo a partir de sua repetição que se faz, inclusive, por meio do discurso.

Jaeger e Goellner (2011) ensinam que o esporte é um espaço que recebe reflexos de relações de poder, incluindo as problemáticas de gênero. Moraes e Silva (2012), trabalhando as problemáticas do sexismo e heterossexualidade no campo esportivo, considera que a hegemonia masculina tem função importante "na economia de controle de corpos, porque contribui para o estabelecimento de espaços e práticas sociais diferenciados, tanto para aqueles e aquelas capturados pela biopolítica e pela matriz heterossexual, quanto para os demais que [...] desviam-se da norma" (p. 352).

Desse modo, a hegemonia masculina no esporte influencia para a diferenciação de práticas entre os atletas, gerando exclusão, e, assim sendo, observa-se o funcionamento do poder disciplinar, pois se exerce um controle sobre as práticas dos indivíduos, delimitando os espaços que podem ocupar. É importante, nesse sentido, considerar os reflexos do poder disciplinar nos discursos.

\subsection{Futebol de Mulheres ${ }^{26}$}

No início do século 20 as mulheres participavam de alguns esportes, no entanto havia restrições. No futebol, apesar de as mulheres o praticarem, consistia em uma participação mínima se comparada à dos homens, inclusive em razão de proibições, decorrentes de decretos oficiais de interdição, que impediam o investimento de políticas de inclusão para as mulheres por parte dos clubes. Essa realidade alterou-se nos anos 70, haja vista que, em 1979, revogou-se o entendimento do Conselho Nacional de Desportos que proibia a participação feminina no futebol e no futebol de salão (GOELLNER, 2005). A primeira Copa do Mundo de Futebol Feminino foi realizada em 1991, na China, cuja organização foi realizada pela Fifa. Tendo em vista o sucesso, a modalidade foi incluída, em 1996, na Olimpíada de Atlanta (CAMARGO; KESSLER, 2017).

Diferentemente da associação realizada no início do século 20 entre mulheres e prática de exercícios físicos, no sentido de que este seria útil para sua saúde e maternidade, nos anos 70 o discurso se alterou, pensando-se na erotização de seus corpos. Um dos argumentos justificadores desse raciocínio era de que geraria maiores públicos aos estádios, e consequentemente, conseguiriam recursos, inclusive mediante a exploração da imagem dessas mulheres, por meio de propagandas, produtos, etc. Uma demonstração desses fatos foi a reedição, em 2001, de um campeonato feminino de futebol conhecido como "Paulistana", no qual havia requisitos para a participação das mulheres (GOELLNER, 2005).

Considerando ser o futebol um esporte que participa da identidade nacional do Brasil, é interessante compreender que ainda carece de maior ocupação pelas mulheres, além de ser necessário (GOELLNER, 2005) "ressignificar alguns dos sentidos que a ele estão incorporados de forma a afirmar que esse espaço também é seu. Um espaço de sociabilidade e de exercício de liberdades" (p. 150). O futebol praticado por mulheres as faz transgressoras, e paralelamente, também as coloca em certo grau de submissão às normas estéticas e outras provenientes das instâncias que organizam a modalidade (CAMARGO; KESSLER, 2017).

Para Camargo e Kessler (2017, p. 197), em que pese a possibilidade de jogarem futebol, "ainda permanecem sem um circuito de competição profissional que seja largamente reconhecido ou que carregue a mesma distinção em termos de prestígio". Em estudo de caso sobre o tema, Souza Júnior (2013) fez pesquisa junto a três equipes que participavam do Campeonato Paulista de Futebol Feminino, realizado em 2011. Entre as conclusões, observou-se a falta de incentivo para que as atletas continuassem fazendo do futebol um projeto de vida, na medida em que, por vezes, não possuem registro em carteira de trabalho, somada à falta de apoio familiar, de estrutura, salários inexistentes ou de pequeno valor.

Em relação à falta de apoio institucional, para que as metas propostas pela Fédération Internationale de Football Association (Fifa) sobre o futebol praticado por mulheres sejam seguidas, é importante a ação das Confederações e Federações afiliadas à Fifa, além da atuação do Estado, da mídia e do âmbito privado. As

\footnotetext{
${ }^{26}$ Kesller (2012) prefere a expressão "futebol de mulheres", ao invés de "futebol feminino", pois esta expressão conecta-se a uma sexualidade ou feminilidade pré-definidas. Ainda, esconde a exigência de performance "masculina" na prática esportiva pelas atletas. Nesse sentido, a expressão defendida pela autora remete à consideração sobre as feminilidades que deveriam ser mostradas pelas jogadoras.
} 
afiliadas da Fifa no Brasil são a Confederación Sudamericana de Fútbal (Conmebol) e a Confederação Brasileira de Futebol (CBF). A CBF, no entanto, não possui uma estrutura adequada para a prática do futebol por muIheres, tanto em âmbito nacional quanto estadual. Além disso, a Fifa não criou estratégias para que a política sobre o futebol para as atletas fosse executada pelas Confederações e Federações afiliadas (SOUSA JÚNIOR, 2013).

Considerando esse contexto, as consequências da falta de atenção às mulheres se refletiram nos clubes estudados, em razão da "ausência de uma configuração político-organizacional da modalidade que estabelecesse condições para um desenvolvimento autossustentável" (p. 299-300). Nesse sentido, o Clube C não possuía meios de dar suporte ao futebol feminino. O Clube A, que apresentava maior potencial, pois usufruía da infraestrutura de um clube profissional, precisou descontinuar as atividades com as atletas, na medida em que faltavam patrocinadores. $O$ Clube $B$, de infraestrutura média, apesar de ainda não fornecer estabilidade às mulheres, teve resultados positivos, garantindo auxílio médico e estrutura para treino (SOUSA JÚNIOR, 2013).

Segundo o autor, esses clubes não seguiam a legislação. Obrigavam o cumprimento de deveres constantes da Lei Pelé, mas não havia remuneração às atletas, que deveria constar de contrato. Diante disso, para se obter igualdade de direitos entre homens e mulheres é preciso que as atletas usufruam das garantias que os homens possuem. Defende-se, desse modo, o reconhecimento de vínculo das atletas com os clubes, políticas afirmativas que deem espaços de decisão às mulheres em entidades como a Fifa e a Conmebol, política pública que preze pela igualdade nesse campo, além de estudos que desmascarem conceitos errôneos, a exemplo da crença de que futebol não deve ser praticado por mulheres (SOUSA JÚNIOR, 2013).

\subsection{Rugby}

Bettine, Gutierrez e Oliveira (2017) entrevistaram ${ }^{27}$ atletas que praticam rugby no Brasil, a fim de compreender como visualizavam a prática do esporte, a feminilidade e "[...] sua luta como mulher em um local dominado por homens". O objetivo foi "entender como elas interpretavam a sua participação em uma modalidade pouco conhecida e atrelada a valores heteronormativos" (2017, p. 149).

As entrevistadas responderam já terem sido alvo de preconceito e que enfrentam resistência para a prática do esporte (BETTINE; GUTIERREZ; OLIVEIRA, 2017). Cumpre ressaltar que "a falta de incentivo para as modalidades femininas é um grande problema presente em todas as modalidades, com as atletas recebendo menos atenção da mídia e menos recursos das suas confederações" (p. 147). A maior parte dos recursos destina-se à modalidade masculina, no entanto as atletas argumentam que justamente por ser o rugby feminino uma área de grande competição internacional, requereria maiores recursos. Perguntadas a respeito das transformações que o esporte trouxe para seus corpos, destacaram que já foram criticadas, especialmente por familiares, em razão de terem um corpo similar ao tido como masculino (BETTINE; GUTIERREZ; OLIVEIRA, 2017).

Em estudo de caso que correlaciona gênero e rugby, Wright e Clarke (1999) destacam que as escolhas discursivas da mídia sobre as atletas desse esporte acabam por reforçar uma heterossexualidade obrigatória. Para compensar o fato de mulheres jogarem rugby, os discursos dão a certeza para os leitores - na maioria homens - de que as atletas são femininas de outras formas, além de que seus jogos não constituem uma intimidação aos atletas masculinos. Os dados foram coletados a partir de jornais australianos e do Reino Unido e criaram-se categorias. Quanto à primeira - descritiva ou explanatória - utilizaram-se como base The Guardian (Jupp, 1996) e jornal universitário (Woolage, 1996). Entre outras conclusões, com base em Jupp (1996), os autores concluem que quando os esportes femininos e masculinos eram comparados, as diferenças normalmente eram descritas de modo a reproduzir desigualdades de gênero por meio do discurso.

A segunda categoria, relacionada à misoginia e antagonismo à prática feminina pelo esporte, estudouMartin Johnson (1997) em The Sunday Telegraph. O discurso ridicularizava e inferiorizava as atletas, bem como abordava de maneira sexista as aparências. Quanto à terceira categoria - simpatizante pela prática, mas heterossexista - averiguaram-se os artigos de Howell no jornal The Sunday Times, de Junee, 1996, em Australian

\footnotetext{
${ }^{27}$ As entrevistas foram realizadas "durante a terceira etapa do campeonato feminino, o Super Sevens, competição mais importante da temporada de rugby feminino reunindo as melhores equipes e atletas" (BETTINE; GUTIERREZ; OLIVEIRA, 2017, p. 144).
} 


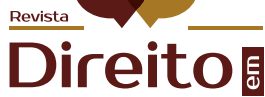 \\ Debate}

A DESIGUALDADE DE GÊNERO NA FÓRMULA 1, FUTEBOL E RUGBY: DESCONSTRUÇÃO DISCURSIVA

Carla Bertoncini - Tayana Roberta Muniz Caldonazzo

Rugby Review e Sheehan, em The Sydney Morning Herald, todos de 1996. O primeiro, embora discurse sobre as atletas com admiração, ainda faz menção à aparência. Além disso, reforça uma heterossexualidade obrigatória. Já o artigo de Junee separava as jogadoras das demais mulheres, e as infantilizava. Observaram-se em Sheehan (1996) e Junee (1996) referências a estereótipos femininos. Os autores ainda mencionam uma quarta categoria, relacionada à sexualidade (WRIGHT; CLARKE, 1999).

Quanto às similaridades entre os artigos, compreendem que a maioria indicava a seriedade das mulheres ao praticarem o esporte, bem como que essa prática não se constitui em uma ameaça à heterossexualidade. Além disso, desconsideravam a existência de mulheres lésbicas (WRIGHT; CLARKE, 1999). Embora esse estudo possua alguns anos, observa-se que a prática de rugby ainda é avaliada de forma negativa, haja vista atribuições de gênero e padrões heteronormativos, conforme Bettine, Gutierrez e Oliveira (2017).

Em suma, há um padrão de problemáticas nas modalidades esportivas estudadas, relacionado a uma estética corporal, normas sobre feminilidade, recursos desiguais, dúvidas sobre capacidade feminina e indagações quanto ao lugar que deveriam ocupar. As desigualdades de gênero estão presentes nos esportes, de modo que a participação de mulheres em um mundo criado e mantido pelo masculino ainda gera recomendações dos homens destinadas às mulheres, além de preconceitos e argumentos atrelados à Biologia para justificar desigualdades injustas (FLORES, 2010; BEAUVOIR, 1970; SILVEIRA, 2013; GOELLNER, 2005, 2007a, 2007b, 2013; BETTINE, GUTIERREZ; OLIVEIRA, 2017), sendo imprescindível ressignificar e alterar esse discurso, para que de fato as mulheres se integrem nesse campo, aproximando-se cada vez mais da igualdade substancial defendida por Bobbio (1993).

\section{CONSIDERAÇÕES FINAIS}

Depreende-se das lições de Maders e Angelin (2010), Goellner (2005, 2007a, 2007b, 2013), Camargo e Kessler (2017), Silveira (2013), Flores (2010), Beauvoir (1970), ser comum encontrar recomendações de que as mulheres não deveriam participar de determinada modalidade esportiva por contrariarem sua natureza ou a feminilidade, no entanto as desigualdades de gênero nos esportes têm bases biológicas ou são historicamente construídas? Há um discurso marcado por atribuições que, perpassando a fronteira temporal, atribui funções para homens e mulheres, delimitando suas possibilidades de movimentos, de modo que tende a contribuir para as desigualdades de gênero no campo esportivo.

A história mostra que modalidades esportivas eram proibidas às mulheres; seus corpos sofreram erotizações; a visibilidade midiática para esportes praticados por mulheres é menor, assim como são os patrocínios; seus corpos podem ser julgados como excessivamente viris se ultrapassarem uma determinada "barreira da feminilidade" (GOELLNER, 2005, 2007a; BETTINE; GUTIERREZ; OLIVEIRA, 2017; SANTANA; SILVA, 2015). Esses fatores podem ser entendidos como barreiras à igualdade substancial de gênero nos esportes, indicando a importância de desconstrução discursiva e ressignificação.

Desse modo, se enaltecem os estudos de gênero no mundo dos esportes, por permitirem concluir que não é a anatomia de um corpo, visto como algo naturalmente dado e imutável, que irá delimitar o espaço de poder da mulher na Fórmula 1, futebol e rugby. Há poderes escondidos em discursos que culpam a natureza e a Biologia por desigualdades injustificadas, inaptas a fundamentar a dominação masculina na Fórmula 1, futebol e rugby. Em Análise de Discurso baseada em Foucault (2008), além das considerações de Butler (2017), verificou-se como se constituiu e se reproduz o cenário de dominação por meio de discursos na Fórmula 1, por exemplo.

Apesar de existirem situações em que um tratamento desigual é bem-vindo, há casos, nos esportes, em que uma abordagem desigual esconde um viés de problemáticas de gênero, mostrando-se injusto, a exemplo de restrições sobre a participação das mulheres. Desse modo, a compreensão das relações de poder envolvidas em discursos - que podem parecer verdades replicáveis - é importante para que se possa transformar o cenário desigual. 


\section{REFERÊNCIAS}

BETTINE, Marco; GUTIERREZ, Diego Monteiro; OLIVEIRA, Alua. Corpo e feminilidade a partir das experiências das jogadoras de rugby brasileiras. Revista Brasileira de Estudos do Lazer, Belo Horizonte, v. 4, n. 3, p. 139-153, set./dez. 2017. ISSN: 2358-1239. Disponível em: https://periodicos.ufmg.br/index.php/rbel/article/view/578/395. Acesso em: 8 maio 2020.

BEAUVOIR, Simone de. O segundo sexo: fatos e mitos. Tradução Sérgio Milliet. 4. ed. Paris: Librairie Gallimard. São Paulo: Difusão Européia do Livro, 1970.

BOBBIO, Norberto. Igualdad y liberdad. Tradução Pedro Aragón Rincón. Barcelona: Paidós, 1993.

BUTLER, Judith. A vida psíquica do poder: teorias da sujeição. Tradução Rogério Bettoni. Belo Horizonte: Autêntica Editora, 2017.

CAMARGO, Wagner Xavier; KESSLER, Cláudia Samuel. Além do masculino/feminino: gênero, sexualidade, tecnologia e performance no esporte sob perspectiva crítica. Horizontes Antropológicos, Porto Alegre, v. 23, n. 47, p. 191-225, jan-abr. 2017. ISSN: 0104-7183. DOI: http://dx.doi.org/10.1590/s0104-71832017000100007

COLOMBIANA TATIANA... Globoesporte.com, Barcelona, Espanha, 6 mar. 2018. Disponível em: https://globoesporte.globo. $\mathrm{com} /$ motor/formula-1/noticia/venezuelana-tatiana-calderon-e-anunciada-como-piloto-de-testes-da-sauber.ghtml. Acesso em: 8 maio 2020

COSTA, Fábio Soares da; SANTOS, Andreia Mendes dos. Diferença e igualdade nas relações de gênero no esporte. Holos, a. 34, v. 5, p. 140-150, nov. 2018. ISSN: 1807-1600. DOI: https://doi.org/10.15628/holos.2018.7607

COSTA, Ariston Flavio; ZAIDAN FILHO, Michel. A busca pela fertilidade das utopias na discriminação por identidade de gênero: análise do panorama jurídico no Brasil e as questões irrespondidas. Revista Paradigma, Ribeirão Preto, a. XXIV, v. 28, n. 1, p. 34-36, jan./abr. 2019. ISSN: 2318-8650. Disponível em: http://revistas.unaerp.br/paradigma/article/view/1132. Acesso em: 8 maio 2020.

DEVIDE, Fabiano Pries; OSBORNE, Renata; SILVA, Elza Rosa; FERREIRA, Renato Callado; CLAIR, Emerson Saint; NERY, Luiz Carlos Pessoa. Estudos de gênero na Educação Física Brasileira. Revista Motriz, Rio Claro, v. 17, n. 1, p. 93-103, jan/mar. 2011. ISSN: 1980-6574. DOI: http://dx.doi.org/10.5016/1980-6574.2011v17n1p93

DUARTE, André. Sobre a biopolítica: de Foucault ao século XXI. Revista Cinética, p. 1-15, 2008. Disponível em: http://www. revistacinetica.com.br/cep/andre_duarte.pdf. Acesso em: 8 maio 2020.

ESFORÇO FÍSICO... GloboEsporte.com, México, 5 mar. 2018. Disponível em: https://globoesporte.globo.com/motor/formula-1/ noticia/esforco-fisico-impede-sucesso-de-mulheres-diz-espanhola-que-ja-testou-na-f1.ghtml. Acesso em: 8 maio 2020.

FLORES, Joaquín Herrera. Construcción de las garantías. Hacia una concepción antipatriarcal de la liberdad y la igualdad. In: SARMENTO, D.; IKAWA, D.; PIOVESAN, F. (coord.). Igualdade, diferença e direitos humanos. Rio de Janeiro: Editora Lumen Juris, 2010.

FOUCAULT, Michel. A arqueologia do saber. Tradução Luiz Felipe Baeta Neves. 7. ed. Rio de Janeiro: Forense Universtiária, 2008.

FOUCAULT, Michel. Vigiar e punir: nascimento da prisão. Tradução Raquel Ramalhete. 20 ed. Petrópolis: Editora Vozes, 1999.

FOUCAULT, Michel. Microfísica do poder. Organização e tradução Roberto Machado. Rio de Janeiro: Edições Graal, 1979.

GIACOMONI, Marcello Paniz; VARGAS, Anderson Zalewski. Foucault, a arqueologia do saber e a formação discursiva. Veredas On-line - Análise de Discurso, Juiz de Fora, v. 14, n. 2, p. 119-129. 2010.

GOELLNER, Silvana Vilodre. Feminismos, mulheres e esportes: questões epistemológicas sobre o fazer historiográfico. Movimento. Revista de Educação Física da UFRGS, Porto Alegre, v. 13, n. 2, p. 171-196, maio/ago. 2007a. DOI: https://doi. org/10.22456/1982-8918.3554

GOELLNER, Silvana Vilodre. Gênero e esporte na historiografia brasileira: balanços e potencialidades. Revista Tempo, v. 19, n. 34, p. 45-52, jun. 2013. ISSN: 1413-7704. DOI: http://dx.doi.org/10.5533/TEM-1980-542X-2013173405

GOELLNER, Silvana Vilodre. História das mulheres no esporte: o gênero como categoria analítica, 2007, Recife. CONGRESSO BRASILEIRO DE CIÊNCIAS DO ESPORTE, 15., CONGRESSO INTERNACIONAL DE CIÊNCIAS DO ESPORTE, 2., 2007. Recife. Anais eletrônicos [...]. Recife: CBCE, 2007b. p. 1-10. ISBN: 978-85-88968-12-7. Disponível em: http://www.cbce.org.br/docs/cd/listaresumos.htm. Acesso em: 8 maio 2020.

GOELLNER, Silvana Vilodre. Mulheres e futebol no Brasil: entre sombras e visibilidades. Revista Brasileira de Educação Física e Esporte, São Paulo, v. 19, n. 2, p. 143-151, abr./jun. 2005. DOI: https://doi.org/10.1590/S1807-55092005000200005

IÑIGUEZ, Lupicinio. A linguagem nas ciências sociais: fundamentos, conceitos e modelos. In: IÑIGUEZ, Lupicinio (coord.). Manual de análise do discurso em ciências sociais. Tradução Vera Lúcia Joscelyne. Petrópolos, RJ: Vozes, 2004a.

IÑIGUEZ, Lupicinio. A análise do discurso nas ciências sociais: variedades, tradições e práticas. In: IÑIGUEZ, Lupicinio (coord.). Manual de análise do discurso em ciências sociais. Tradução Vera Lúcia Joscelyne. Petrópolos, RJ: Vozes, $2004 b$. 
JAEGER, Angelita Alice; GOELLNER, Silvana Vilodre. O músculo estraga a mulher? A produção de feminilidades no fisiculturismo. Estudos Feministas, Florianópolis, v. 19, n. 3, p. 955-975, dez. 2011. DOI: http://dx.doi.org/10.1590/S0104026X2011000300016

KESSLER, Cláudia Samuel. Se é futebol, é masculino? Revista Discente do Programa de Pós-Graduação em Sociologia da Universidade Federal do Paraná, número especial 1, 2012. Seminário Nacional de Sociologia e Política, 4. DOI: http://dx.doi. org/10.5380/sclplr.v0i1.64807

LAQUEUR, Thomas. La construcción del sexo: cuerpo y género desde los griegos hasta Freud. Tradução Eugenio Portela. Madrid: Cátedra, 1994.

LIMA, Francielle Elisabet Nogueira. Perspectivas críticas sobre a tutela jurídica de pessoas trans: diálogos entre estudos (trans) feministas e direito. 2018. Dissertação (Mestrado) apresentada ao Programa de Pós-Graduação em Direito do Setor de Ciências Jurídicas. Curitiba: UFPR, 2018.

MACHADO, Roberto. Foucault, a ciência e o saber. 3. ed. Rio de Janeiro: Zahar, 2007.

MADERS, Angelita Maria; ANGELIN, Rosângela. A construção da equidade nas relações de gênero e o movimento feminista no Brasil: avanços e desafios. Cadernos de Direito, Piracicaba, v. 10, n. 19, p. 91-115, jul./dez. 2010. ISSN: 2238-1228. DOI: http:// dx.doi.org/10.15600/2238-1228/cd.v10n19p91-115

MELLO, Celso Antônio Bandeira de. O conteúdo jurídico do princípio da igualdade. São Paulo: Malheiros Editores, 2002.

MONTEIRO, Caroline Barbosa; FORMENTIN, Claudia Nandi. Mulher no volante: a presença feminina na F1 em publicações do globoesporte.com. Ces Revista, Juiz de Fora, v. 33, n. 1, p. 209-204, jan./jul. 2019. ISSN: 1983-1625. Disponível em: https://seer. cesjf.br/index.php/cesRevista/article/view/2020. Acesso: 8 maio 2020.

MORAES E SILVA, Marcelo Moraes. Escola e educação física: maquinaria disciplinar, biopolítica e generificante. Rev. Bras. Ciênc. Esporte, Porto Alegre, v. 34, n. 2, p. 343-357, jun. 2012. DOI: https://doi.org/10.1590/S0101-32892012000200007 MOREIRA, Adilson José. Cidadania sexual: estratégia para ações inclusivas. Belo Horizonte: Arraes Editores, 2017.

NINA, Roberta. Por que não há mulheres na Fórmula 1: capacidade ou oportunidade? Uol, 25 abr. 2019 , blog Dibradoras. Disponível em: https://dibradoras.blogosfera.uol.com.br/2019/04/25/por-que-nao-ha-mulheres-na-formula-1-capacidade-ou-oportunidade/. Acesso em: 8 maio 2020.

NUNES, Danilo Henrique; SILVA, Juvêncio Borges. O direito fundamental ao trabalho e à equidade racial e de gênero: condição da efetivação da igualdade no âmbito das relações de trabalho. Revista Direito e Liberdade, Natal, v. 21, n. 3, p. 85-126, set./ dez. 2019. ISSN: 2177-1758. Disponível em: http://ww2.esmarn.tjrn.jus.br/revistas/index.php/revista_direito_e_liberdade/article/view/1996. Acesso em: 8 maio 2020.

ORLANDINI, Eni P. Análise de discurso: princípios e procedimentos. 5. ed. Campinas, SP: Pontes, $2003 a$.

ORLANDINI, Eni P. A Análise de discurso em suas diferentes tradições intelectuais: o Brasil. In: SEMINÁRIO DE ESTUDOS EM ANÁLISE DE DISCURSO, 1., 2003. Porto Alegre, Anais [...]. Porto Alegre: Ed. da UFRGS, 2003b. p. 1-18. Disponível em: http:// analisedodiscurso.ufrgs.br/anaisdosead/1SEAD/Conferencias/EniOrlandi.pdf. Acesso em: 8 maio 2020.

RIOS, Roger Raupp. Direito a antidiscriminação, sexo, sexualidade e gênero: a compreensão da proibição constitucional de discriminação por motivo de sexo. In: SARMENTO, D.; IKAWA D.; PIOVESAN, F. (coord.). Igualdade, diferença e direitos humanos. Rio de Janeiro: Editora Lumen Juris, 2010.

SANTANA, Daiane de Oliveira; SILVA, Grasiela Oliveira de Santana. O papel da mulher dentro do contexto esportivo: uma análise a partir do futebol. ENCONTRO INTERNACIONAL DE FORMAÇÃO DE PROFESSORES E FÓRUM PERMANENTE DE INOVAÇÃO EDUCACIONAL, 8., Anais [...], v. 1, n. 8, 2015. ISSN: 2179-0663. Disponível em: https://eventos.set.edu.br/index.php/enfope/ article/view/1562. Acesso em: 8 maio 2020.

SCOTT, Joan W. O enigma da igualdade. Revista Estudos Femininas, Florianópolis, v. 13, n. 1, p. 11-30, jan./abr. 2005. ISSN: 1806-9504. DOI: https://doi.org/10.1590/S0104-026X2005000100002

SCOTT, Joan. Gênero: uma categoria útil para análise histórica. Tradução Christine Rufino Dabat e Maria Betânia Ávila. Texto original: Gender: a useful category of historical analyses. Gender and the politics of history. New York: Columbia University Press, 1989. Disponível em: https://edisciplinas.usp.br/pluginfile.php/185058/mod_resource/content/2/G\%C3\%AAnero-Joan\%20Scott.pdf. Acesso em: 8 maio 2020.

SILVA, André dos Santos; NAZÁRIO, Patrícia Andrioli. Mulheres atletas de futsal: estratégias de resistência e permanência no esporte. Revista Estudos Feministas, Florianópolis, v. 26, n. 1, e40862, p. 1-15, 2018. ISSN: 0104-026X. DOI: http://dx.doi.org/10.1590/1806-9584.2018v26n140862

SILVEIRA, Viviane Teixeira. Tecnologias e a mulher atleta: novas possibilidades de corpos e sexualidades no esporte contemporâneo. 2013. Tese (Doutorado) - Universidade Federal de Santa Catarina, Programa de Doutorado Interdisciplinar em Ciências Humanas (PPGICH), Florianópolis, 2013.

SCHWARCZ, Lilia Moritz. Sobre o autoritarismo brasileiro. São Paulo: Companhia das Letras, 2019. 


\section{Direito \\ Debate}

\section{A DESIGUALDADE DE GÊNERO NA FÓRMULA 1, FUTEBOL E RUGBY: DESCONSTRUÇÃO DISCURSIVA \\ Carla Bertoncini - Tayana Roberta Muniz Caldonazzo}

SOUSA, Noelma Cavalcante de; MENESES, Antonio B. N. Thomas de. O poder disciplinar: uma leitura em vigiar e punir. Revista Saberes, Natal, RN, v. 1, n. 4, p. 18-35, jun. 2010.

SOUSA JÚNIOR, Osmar Moreira de Souza. Futebol como projeto profissional de mulheres: interpretações da busca pela legitimidade. 2013. Tese (Doutorado) - Universidade Estadual de Campinas, Pós-Graduação da Faculdade de Educação Física, Campinas, 2013.

TIBURI, Marcia. Feminismo em comum: para todas, todes e todos. Rio de Janeiro: Rosa dos Tempos, 2018. Recurso Digital, formato Epub.

TORRÃO FILHO, Amílcar. Uma questão de gênero: onde o masculino e o feminino se cruzam. Cadernos Pagu, Campinas, n. 24, p. 127-152, jan./jun. 2005. ISSN: 1809-4449. DOI: http://dx.doi.org/10.1590/S0104-83332005000100007

WRIGHT, Jan; CLARKE, Gill. Sport, the media and the construction of compulsory heterosexuality. International Review for the Sociology of Sport, London, 34, p. 227-243, 1999. DOI: https://doi.org/10.1177/101269099034003001 